\title{
Discussion on the Modern State Audit Resources Integration
}

\author{
Zhang Shuang \\ Department of Management and Engineering, The Officers' College of CAPF, Shuangliu, Chengdu, Sichuan, China
}

\begin{abstract}
This paper starts from the analysis of the integration of modern state audit resources in China, based on the study of national audit resources integration is arranged on the principle, put forward the construction goal, the general idea of integration of national audit resources integration and the construction of supporting facilities of the resource elements.
\end{abstract}

Keywords -state audit, audit resources, integration

\section{对现代国家审计资源整合的探讨}

\author{
张爽 \\ 中国人民武装警察部队警官学院管理科学与工程系
}

\begin{abstract}
摘 要 本文拟从分析我国现代国家审计资源整合的特点入手, 在探讨设置国家审计资源整合原则的基础上, 提出了以建设目标, 资源要素整合和配套设施建设为主的国家审计资源整合总体思路。
\end{abstract}

关键词 国家审计，审计资源，整合

现代国家审计资源是指, 新世纪、新阶段, 为履行我国 现代化建设的历史使命, 由国家审计机关掌握或可供国家 审计部门利用的, 确保完成现代国家审计任务, 实现现代 国家审计目标的社会资源。由于国家审计资源所涉及的内 容十分宽泛，为整体提高审计工作的政治和经济效益，提 高国家审计资源的利用率。采取科学合理的思路来整合国 家审计资源，使其发挥整体效益是值得研究的问题。

\section{1. 现代国家审计视角下的资源整合特点}

\section{1 伴随国家发展, 整合目标有所突破}

国家审计资源整合目标应该与我国的发展相一致, 与 国家审计建设进程相适应, 与我国所处的时代背景和历史 条件相融合。现代国家审计主张以“审计目标效益化、审计 手段信息化、审计体制扁平化、审计人才复合化、审计活 动法制化、审计管理科学化”为战略目标, 给国家审计资源 整合提出了新要求, 是对传统国家审计的突破和超越, 具 有鲜明的时代特征和现代化气息。

\section{2 伴随内涵转变, 外部资源成为整合的对象}

“由挖掘内部资源转变为整合内外部资源”是现代国家
审计内涵特征的主要体现之一。一方面, 审计资源无法满 足我国审计发展需要的现状, 促使我们必须破除资源困境, 谋求现代国家审计的顺利实现。从我国审计工作发展的现 实来看, 走“精兵之路”是现代国家审计的发展方向, 通过 资源整合走“内涵式”发展道路，便顺理成章地成为建设现 代国家审计的内在之需。这是“整合资源”成为现代国家审 计内涵特征的重要原因; 另一方面, 以往通过加强国家审 计机关自身建设、挖掘内部潜力等途径来解决国家审计资 源不足, 虽然取得了丰硕的成果, 但内部资源毕竟有限, 在建设现代国家审计的漫长过程中, 国家审计机关与外部 组织的相互联系和依赖日益加强, 外部资源必将受到关注。 从审计发展历程来看, 重视外部资源几乎无一例外地成为 建设“现代审计”的必经之路。以加拿大国家注册审计师协 会为例, 专门制定了国家审计、内部审计和民间审计的通 用审计准则和审计标准, 为实现社会审计、内部审计和国 家审计资源整合提供了法规依据, 促使国家审计可以有效 整合和利用外部资源, 提高审计效率。实践证明, 重视外 部资源既是国家审计发展的产物, 也是现代国家审计必须 遵循的规律。因而外部资源理应成为现代国家审计视角下 资源整合的必要对象。 
1.3 伴随社会进步, 信息资源整合成为整合的重要内容

随着社会的进步, 信息已经成为现代社会的主要标志, 在现代国家审计中扮演着不可或缺的角色。信息资源整合 已成为现代国家审计视角下资源整合的重要内容, 这是有 别于传统审计资源整合的显著特征。审计信息工作作为审 计基础建设的一项, 要以顶层设计为牵引, 大力加强审计 信息化建设, 紧跟国家信息化建设的步伐, 大力整合现有 审计信息资源, 进一步加强网络审计交流, 逐步实现我国 审计信息资源共享; 作为现代国家审计战略构想, 要努力 实现“标准统一、结构合理、信息共享、信息互通的国家审 计网络系统”。可以看出, 随着时代的发展, 信息资源在国 家审计中的作用越发重要, 理论界对信息资源予以前所未 有的关注。近年来, 特别是在建设现代国家审计中, 整合 国家审计信息资源已经成为国家审计的历史性任务, 被提 到战略的高度, 这是传统国家审计所不具备的。

\section{2. 国家审计资源整合的思路架构}

\section{1 国家审计资源整合的原则}

(1)谋求长远利益, 找准整合目标。国家审计资源整合 不仅应当成为解决当前资源困境的权宜之计, 还必须有益 于我国审计的长远发展, 成为促进国家审计发展的长久之 策。因此, 设计的国家审计资源整合途径、构建的整合思 路和运用的整合措施都要符合国家审计战略发展的需要。

现代国家审计目标与我国审计工作的长远发展具有一 致性。一方面, 全面建设现代国家审计是我国审计工作面 临的重大课题, 是现阶段国家审计所担负的重大使命, 也 是当前形势和环境赋予国家审计的重大任务, 具有深刻的 历史烙印和鲜明的时代特征, 它是现代国家审计发展的现 实目标。另一方面, 现代国家审计代表国家审计发展的方 向, 是确保国家审计能够适应和满足我国现代化建设需要 的关键环节。从这一点来说, 实现了现代国家审计就能确 保国家审计长远利益的实现。因此, 按照现代国家审计的 要求实施资源整合, 促进现代国家审计的顺利实现, 既有 利于国家审计当前利益也符合国家审计长远发展, 是国家 审计资源整合的总目标。

(2)结合实际情况, 立足我国现实。国家审计资源整合 要对资源配置的薄弱环节进行调整, 对资源利用的不合理 状况进行改善, 势必会改变现有利益格局, 从而触碰某些 部门、某些领域的“敏感神经”, 给我国审计领域乃至全国 范围内带来“阵痛”, 因而国家审计资源整合遭遇的阻力不 容忽视。在这种情况下, 如果脱离我国现实情况, 不分轻 重缓急地盲目追求整合成效, 不仅会使国家审计机关丧失 应有的支持和配合, 还会增加整合成本, 增大整合阻力。
因此服从和利用我国现实条件, 根据我国审计所处的特殊 环境探索国家审计资源整合途径, 增强整合措施的可行性, 是必须遵从的基本前提。

(3)把握要素特点, 统筹系统整合。国家审计资源整合 过程涉及方方面面, 希望一劳永逸地解决我国审计面临的 资源困境, 显然是不切实际的。为避免整合途径和措施之 间的交叉、矛盾、脱节, 需要按照各审计资源要素的特点, 以总体目标为方向, 设定各资源要素整合的分目标, 有所 针对地解决问题, 才能最终达成审计资源整合目标。但是 各资源要素并非孤立存在, 它们相互联系、相互依赖, 必 须以“协调”为基本理念, 探寻系统、全面、协调的整合, 保证各资源要素协调、互补, 促进现代国家审计的实现。

\section{2 国家审计资源整合的具体思路}

根据上述原则, 国家审计资源整合的总体思路可以概 括为: 围绕建设现代国家审计设计整合途径, 以各资源要 素的整合为主要内容, 以充分的配套措施为保证, 促进现 代国家审计的顺利实现。

(1)围绕建设现代国家审计设计整合途径。管理学认为, “目标”对组织而言有着举足重轻的地位, 它可以发挥方向 作用、激励作用、凝聚作用和考核作用, 从而使组织沿着 正确的方向和路径完成任务、达成愿望。现代国家审计视 角下的审计资源整合目标是促进现代国家审计的实现, 因 此整合思路的构建和途径设计都要紧紧围绕这一目标, 各 项整合工作都要以此为前提, 才能化解困难, 排除障碍, 不至于迷失方向, 陷入盲目之中。

(2)以各资源要素的整合为主要内容。为了避免整合中 的交叉和矛盾, 一方面需要针对各资源要素特点, 从要素 出发, 实现资源整合, 另一方面需要顾及资源要素间相互 依赖的关系, 才能使整合全面有效。具体来说, 第一, 组 织资源整合规定了其他资源的流向。尽管组织资源是其它 资源的载体, 但资源要素各有特点, 组织资源整合并非资 源整合的全部内容, 加之组织资源整合的效果如何, 还待 实践验证, 因而有必要在组织资源整合实现之前的既定条 件下, 根据各要素的特殊性, 探讨其它资源要素的整合途 径和措施。第二, 人才资源整合是国家审计资源整合的基 础。国家审计人才资源整合主要依靠组织资源整合得以实 现, 对现代国家审计而言, 还要引进外部人才资源, 实现 内外人才资源的全面整合。第三, 财力资源整合是国家审 计资源整合的物质保障。财力资源对组织资源有较强依附 性, 在现代国家审计中, 有必要形成符合我国特色的国家 审计财力资源保障机制, 实现财力资源的整合。第四, 信 息资源整合是国家审计资源整合的核心。虽然组织资源和 人才资源的整合在一定程度上能够促成审计信息资源的交 
流和共享, 但现代国家审计的信息化特征, 要求必须将审 计信息资源按照“信息化”的方式进行整合。第五, 技术方 法资源整合是国家审计资源整合的关键环节, 它是确保完 成审计任务的重要“软件”。通过组织资源和人才资源的整 合, 可以使技术方法资源在具体审计业务中得到静态整合, 有必要进一步依据技术方法资源的发展规律和特点, 从历 史的、动态的角度对技术方法资源整合作出研究。

(3)以充分的配套措施为保证。国家审计资源整合涉及 范围广、主体多、任务重, 在各资源要素整合中, 必须根 据实际情况, 做好相关配套措施, 以减少阻力, 保证整合 顺利实现。充分的配套措施包括: 机制准备、與论保证和 法规保证。机制准备主要指协调和激励机制。协调机制是 为了使国家审计资源整合涉及的各个部门、专业领域能够 齐心协力、互相协作, 形成正常有序、和谐统一、优势互
补的良好局面; 激励机制是为了鼓励先进、化解阻力, 确 保国家审计资源整合工作沿着正确的途径展开。與论保证 主要是通过媒体宣传、與论督促等形式, 树立广大人民“以 国家的全局发展为重”的思想, 使国家审计资源整合工作取 得地方党委支持、获得相关业务部门的配合。法规保证就 是根据国家审计资源整合的进程和需要, 不断完善法规, 从“制度”的高度确保整合完成。

\section{参考文献(Reference)}

[1] SongWei-ming. Principles of Management. Chinese Forestry Press. 2002

[2] Wang Shun-bao. Thinking on Perfecting the Audit Mechanism Under the New System. Logistic Science.2004 